\title{
SURFACE-TO-SEABED SAFETY: ADVANTAGES OF SIMULATOR PRACTICE FOR SUBSEA INSTALLATION
}

\author{
L. VEDERHUS \& Y. PAN \\ Faculty of Maritime Technology and Operations, Norwegian University of Science and Technology, Norway
}

\begin{abstract}
Controlling elements of massive weights from surface to seabed and manoeuvring components in narrow spaces within employed modules are just some of the challenges in subsea installations. We report from a specific case of training and installation in a gas field off the Norwegian coastline. Here, two compressor trains, installed at a depth of about $300 \mathrm{~m}$, now enhance exploitation of field reserves and diminish air pollution by eradicating gas compression from the surface to subsea process. In order to reduce risk and increase efficiency, simulator facilities are essential to enable procedure exploration and change, and to elaborate on mental models of subsea operations. The assembled cooperating crew alternates roles of action and observation during simulation sessions, thus allowing a more complete picture of the operation. The simulation sessions are reported to have speeded up the installation, indicating risk mitigation. We encourage further research on procedure investigations by utilisation of the simulator for subsea activities.
\end{abstract}

Keywords: infrastructure, safety, simulator, subsea.

\section{BACKGROUND AND METHODS}

Most resources in the oceans are presumed to still be unexplored, and new challenges arise as new demands are placed on existing offshore activities, from surface to seabed. Safe operation is required both in explorations, installations, and inspection, maintenance and repair work ahead. To comply with these needs, simulations accommodate preparations for both standardised and unique operations comprising risks and hazards. The unique installation simulation process presented is a preliminary case study of demanding ocean activities. The complexity of advanced operations can be analysed in a multitude of ways, and ideas of complexity and theories of complex adaptive systems (CAS) have guided our approach [1-3].

The purpose of this case study is to identify some advantages of simulator practice to subsea installation. The paper is structured to first set the stage by describing the case in terms of the process infrastructure, the simulator facilities, the preparation sequencing, and the hierarchy of running a subsea operation. Next, we emphasise some findings of the preparation advantages. These advantages are mostly extracted from analysis of post-installation interviews with key personnel partaking in the intersecting phases of planning, development, and execution of operational simulation. Key actors interviewed represented the oil and gas company, the engineering company, the simulator centre, and the university course department. Some documents owned by the university course department were included, to ground the interview questions for them, and add to the understanding of the preparation. In analysing the information, we applied a structure of first and second cycle coding, as Saldaña [4] suggests for qualitative research, but due to the exploratory nature of the study, many first 
cycle techniques were mixed. A more consistent application may be used for more specific research questions.

A short discussion with suggestions of additional improvement conditions follows the findings. Being researchers, we are aware of the limitations of the paper for findings of comprehensive risk understandings in such operations, due to the unidirectional search for positive effects in the given approach. We will argue that other publications should include potential neglected or ignored risks, both physical and human elements related, for instance arising from software limitations, time pressure in development efforts, decision making and priorities of operational contents, and dialectical issues of presence and absence concerning complexity management, responsibilities, liabilities, authority regulations, and structures for experiential sharing and learning.

\section{THE SUBSEA CASE}

The factory, now installed at seabed about $300 \mathrm{~m}$ below the surface, has a lifetime expectancy of 25 years, and consists of two compressor trains enhancing the exploitation of gas field reserves and diminishing air pollution by eradicating compression from the surface. The templates are 'the size of a football field', as informants stated, and the modules installed in this operation have had weights up to around 300 tons.

\subsection{Process infrastructure: the organisational entities involved}

In this case, the oil and gas company was the owner of the installation operation. It further engaged an engineering company to provide the procedure for the operation and personnel for the specific operational work, including remotely operated underwater vehicles (ROV) and crane crew. Due to project load, an additional supplier was hired for the ROV work, of which some were reported to have experience from the vessel. The ship owner company has a contract for this vessel with the oil and gas company. The vessel was modified for this operation. The simulator centre was responsible for implementing the required software functionality and equipment representations, and the university course department arranged the human resources instruction and course framing. Further, many sub-suppliers of equipment were represented for development and information exchange (Fig. 1). The estimated number of people involved in the process was around 200, and the number of participants in simulation was around 90.

The process of intersecting phases of planning, development, and execution of operational simulation in this specific case has to be highlighted as the main frame for safety premises. Actors in this case have pushed the process with their respective interest and importance

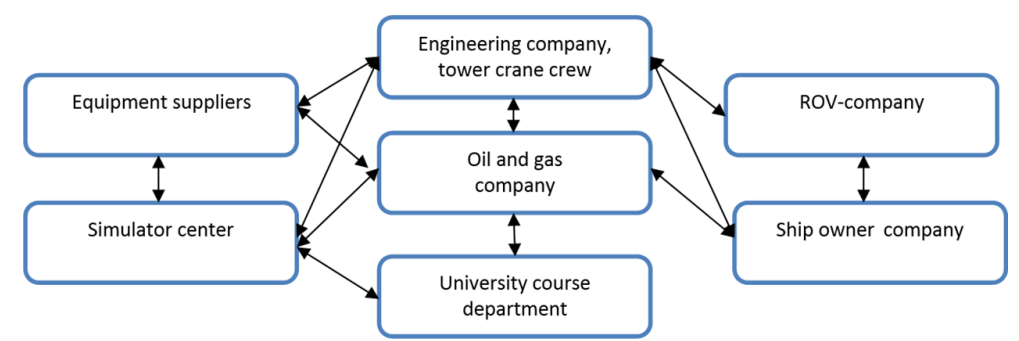

Figure 1: Process infrastructure. The arrows may not be exhaustively represented, and neither reciprocity nor balanced exchange can be assumed, as development demands fluctuate. 
issues, as also stated by one of the informants: 'different people have different opinions on what is actually a critical operation', but the premises are owned by the oil company who have had the final decision on priorities.

\subsection{The simulator: sceneries, stations, and scenarios}

The simulator is built for complex operations. The scenery is a reflection of the real environment to operate in, like oil fields with rigs, or seabed locations. Also, the vessel to operate from is modelled after the real vessel. Although some of the fixed equipment at the simulator stations may be other than on-board, they have generic properties and are highly up-to-date. Operators are located at stations that are separate, each with their actual view, and crews preparing for an operation alternate in practicing at the station and observing all stations from the observation room displaying camera monitoring. The stations can be run individually if one wants, but for complex operations, the coordination between stations is often the critical part. The simulating facilities consist of bridges, ROV-station, cranes, deck, and control room for coordination. The simulator will also develop a dive station, to be fully able to meet the needs for complex subsea operational simulation, and two bridges allow for operations with two interacting vessels. Further, there are instructor rooms with full monitoring, to inspect, supervise, and develop scenario-specific interventions for the purpose of preparation and training. Scenarios are mainly based on the critical parts of procedures and the operator's need for preparation. The scenarios, or cases, chosen in this subsea preparation were agreed upon between the engineering company and the oil and gas company, and the simulator centre delivered the functionality for these scenarios to be played out.

\subsection{Preparation by simulation}

The preparation can be expressed in timeline stages (Fig. 2). There is a cyclic pattern of the preparation as this ran for four consecutive days. The preparation was scheduled for three weeks spread over about three months. A refresher session in the simulator immediately before the operators were boarding the vessel for their shift was also added in this operation.

\subsection{Running a subsea operation}

The hierarchy of running the subsea operation is based on information from one key informant, and the positions (and their responsibilities in parentheses) are shown in Fig. 3.

The shift supervisor has a coordination position in the subsea operation, with high attention and communication workload. The subsea engineers have been supporting the procedure

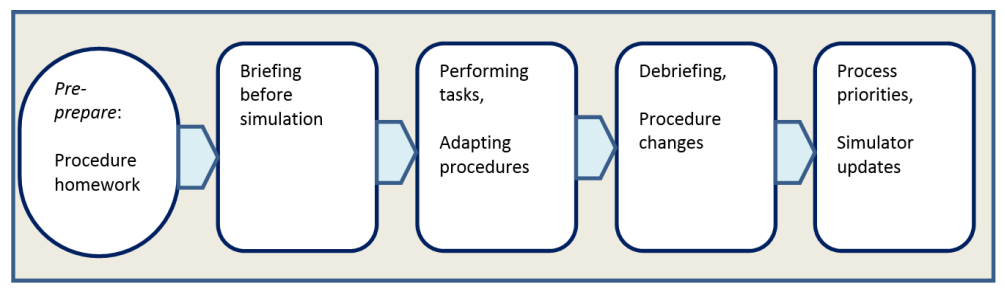

Figure 2: Preparation components. 


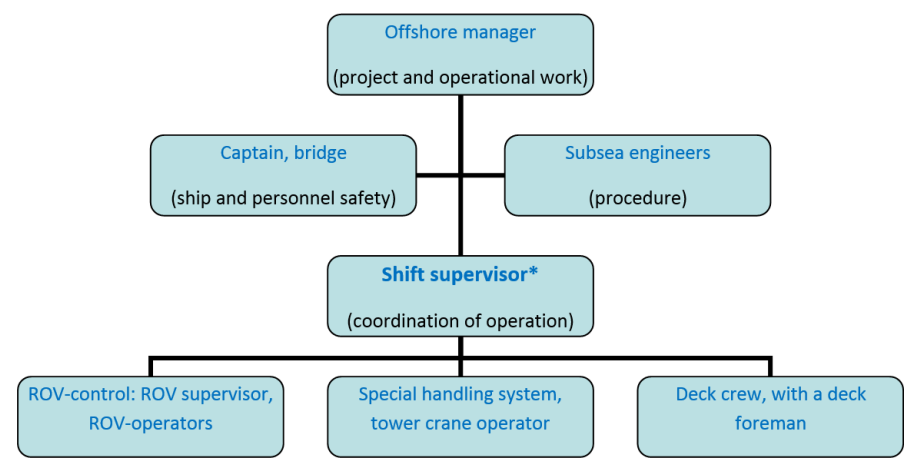

Figure 3: The hierarchy of running the subsea operation.

* The shift supervisor has the central role during the operation: 'the director of the orchestra' (informant quote)

progress. Vessel crew has had the responsibility for DP-operational phases and heading of the vessel for operational outcomes, as well as ballasting adjustment to vessel loadings.

\section{FINDINGS}

The focal point of this analysis is the advantages of simulation to subsea installation. The identification process has run in coding cycles, where interviews rich in information on both simulation as a process and general issues of concern to the organisations have been condensed into four main topics of advantages: the performance improvement of participants, the subsea installation procedure verification, the virtual prototyping of products, and the safety surveillance placement optimisation. In addition, there are identifiable advantages for future safety work from the infrastructure connectivity, where the actors have established an informal network of innovative progress. The simulator centre has benefited from the process by adding new and permanent component feasibilities to a highly flexible system of simulation modules by obliging to the demands of the oil and gas company as well as to the engineering company, although the success story told after the installation may colour the assessment of advantage reported. The ROV stations were built to meet the need for this specific installation operation, and dynamic positioning of the vessel (DP module) was added during preparation. Next, we will elaborate on each of the four main topics of advantages.

\subsection{Performance}

The first advantage of simulation is the performance improvement of participants. Many simulators offer operator training for new workers and standardised operations, and some simulators offer training for teams on human resources and communication, owing to the fact that human errors are reported to be involved in more than 70 percent of maritime incidents and accidents. In this specific case, the personnel were quite experienced and preselected for this demanding operation, and the informants mentioned some hesitance of participants towards the requirements of a training course before the operation. The discrepancies between the university course department's ideas of training and the experienced and preselected personnel's ideas of their competence may have been an initial obstacle to 
the preparation. During the process, however, the attitudes changed, and some of our sources report that this was regarded the 'best familiarisation session ever'. However, using the word familiarisation, or even more broadly for the whole process, preparation instead of training, seems to correspond better with the actual operational challenges for unique operations. Some common training elements can still be identified in this case, especially in the ROV logistics and the shift supervisor's coordination of the crew. Reminders of clear and concise communication appear to have had many benefits for the installation operation. One clear-cut report of the preparation improvement comes from this statement from one informant after installation was completed: 'Work that might have taken like twelve hours, took around four'. The familiarisation gains for the ROV operators flying both the two work class ROVs and the observation ROV may be identified in the speed of repositioning for work around the big modules to be landed on guideposts down on the structures, in working with about 300 connection points, and in movement in ROV corridors. Metaphorically, the improvement is like the difference of driving a car in a new city versus knowing the route and what to expect around the next curve of a familiar road. The behaviour is adapted to the uncertainties out of sight. Preparation by performing some critical procedure parts seems to have revealed the uncertainties and risks, and smoothed the interaction between the assembled crew. 'The operators were more confident when going offshore', stated an informant.

\subsection{Procedure}

This statement from one of the informants shall open the second section of advantages: 'A procedure is dynamic until the installation is complete'. The priorities and decisions on what critical parts to be prepared were made by the oil and gas company in cooperation with the engineering company, and lifting of the huge modules, sling-out, lowering, and entering and landing (deployment) to seabed templates have been reported to be the main acts to prepare. Although the simulator potentials are reported to have expanded the ideas of possible scenarios, the demands have been negotiated between the oil and gas company and the simulator centre, and the constant adding of new simulation modules seems first and foremost to be based on the potential benefits for testing procedures under different circumstances, and guarantee the real complexity of offshore operations. The initial procedure cases have thus been elaborated on rather than replaced, and performing the procedural tasks are said to have led to a large amount of minor changes to the procedure. The presence of the engineers responsible for the procedure specifications have enabled both immediate changes and larger management of change in more complex situations, as well as continuous revisions in the written procedure. This testing and verification process also led to some equipment changes, adding to the safety of the operation.

As mentioned previously, participants were given portions of the procedure delivered by the university course department as homework before arriving at the simulation session. This was meant to compel them to meet somewhat prepared. The procedure was further 'orchestrated' by the shift supervisor along the simulation session, like his normal responsibility in a subsea operation, but the process of improvement was also strongly influenced and pursued by the performance evaluator from the oil and gas company and the subsea engineers responsible for procedure. The interdependence of the performance and procedure improvement is illustrated in fig 4 . 


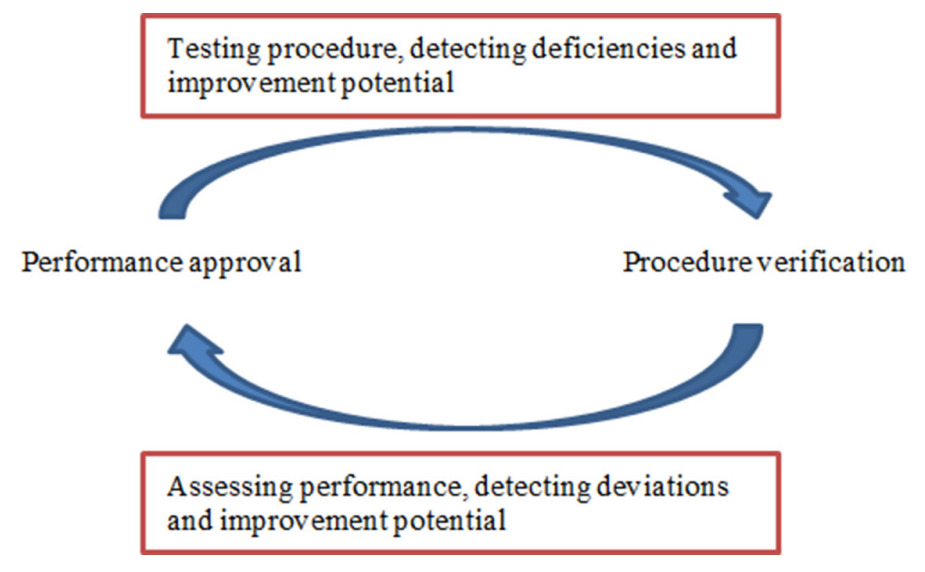

Figure 4: Performance and procedure improvements are interwoven.

\subsection{Products}

The third advantage to highlight will be limited to the products emerging from this subsea simulation process, not equipment changes for the subsea installation, since these are mentioned in the procedure section and were modelled into the simulator as the decisions were made. One of the reported advantages is the virtual prototyping possibility of the equipment suppliers when they are advancing the product during preparations. In this case, the special handling system, or tower crane, was fitted to the operation with features that were not attained to test in the simulator, and one informant said that this was due to the supplier's workload. Some of those advanced functions could have had benefits for the operation, especially for emergency or contingency scenarios, which were not simulated.

The development of a 3D navigation system, with a screen for visualisation, was one of the highlighted strengths in this operation, and the simulator nav-screen enabled the operators to have 'the position of the vessel, and dynamic position of the lifting object, and dynamic positions for all the ROVs relative to the static position of the subsea template', as per one informant. This was further extended to be implemented on-board, with an augmented subsea system with dynamic updated positions, and 'unlimited line of sight', as per the same informant, which was also expressed by other informants to be like 'turning the lights on', since 'down in the template it is just a black hole', to quote one informant, or 'as in the real subsea world you can only see like $2 \mathrm{~m}$ in front of you', to quote the previous informant.

A more general impression of the simulator was offered by one informant: 'The animation was so real and alive, and also the communication system was so good that the shift supervisors and the ROV part were really... well, leaning themselves into the positions the same way as they are doing offshore. ... This was quite extraordinary in fact'.

\subsection{Placement of surveillance cameras}

The last point to discuss is the risk mitigation by camera positioning on the vessel for a complete inspection visibility on deck. Around 25 cameras were rigged on-board based on the simulation session, and adjusted to facilitate cleared deck to avoid the hazards of people on deck during some of the most critical phases. The size of the modules to be handled was reported to be such a criticality. Deck crew could perform the 'knocking them out' of 'sea 
fastening hydraulic pistons, just shot through the module locking it into sea', to quote one informant, but in this instance, the hydraulics was just controlled from the control room, and the simulator was equipped with the cameras intended to be used offshore, to enable surveillance of the deck, and check if 'it is actually unlocked', as the informant stated. This enabled the engineer to test the placement or positioning of safety surveillance. To quote the informant: 'he went in the simulator and he could see what he could actually see on that camera, and he said, "ah, this is not what I want, I want it 2 meters up" and basically they ended up placing the cameras because of that'.

The findings are somewhat limited to improvements perceived from the positions of the organisational representatives, each with their agendas and future perspectives. Simulator implementation followed from the oil and gas company's decisions, and this was reported to be 'more or less the first time they have done typical virtual prototyping'. Professional feedback from the engineering company assisted the oil company in the decisions, but this represents only technological aspects, in a way that dynamically establishes a development infrastructure in which instructors and operators are omitted during negotiations between oil company and other technical suppliers. Evaluation of performance was also conducted by a consultant hired by the oil and gas company, and instructors and operators were still not enrolled in the development infrastructure during the implementation of simulation, so understandings of team preparation from instructors' and operators' perspectives have not been included. The shift supervisor from the engineering company also evaluated performance, with assistance from other subsea engineers, raising further questions of the power relations between the two different infrastructures - the development infrastructure (oil and gas company, engineering company, and simulator centre) and the team preparation infrastructure (instructors and performers). The infrastructures that ideally shall be coordinated for the subsea simulation course to be a successful toolkit, may in this case reveal a vulnerability of the evaluation process, where absence of the operators in the development infrastructure may lead to a shortage of performance evaluation. The pre-preparation and evaluation forms were created by the instructors from the course department, but professional terms were not explained, nor defined, and this challenged its application.

The subsea simulation progress would benefit from further collection of information from all 90 participants. Moreover, a list of refinement suggestions could have been compiled from the existing material, but that is of more interest to the simulator developers, and of less relevance to the audience of this paper. Hence, in order to benefit both sides of infrastructures, we discuss our findings, on the one hand, based on organisational theory in technology studies to evaluate the simulation implementation process. On the other hand, we consolidate the abilities of instructors and operators within the infrastructure of technology-in-use to discover a valuable way for merging two infrastructures towards a more beneficial objective for the oil and gas company as well as for the people who really practice the procedures and products.

\section{DISCUSSION}

Whereas the development priorities were decided by the oil and gas company, though supplemented by the technical engineering company, the end user (operator) seems to have been less involved. System development was based on the oil and gas company's requirement. Bannon argues that end users are not novices [5]; in professional fields, they may have more competencies than engineers and technicians, since they live in their work environments and carry out their jobs on a day-to-day basis. Having focused on describing the system process so far, we also want to emphasise the team preparation in subsea operations, from an 
organisational perspective. The company assigned operators to work in the subsea training program. From the informants, we learned that operators had limited motivation for the subsea preparation sessions because they felt somewhat forced, but embraced it later on because the content fit their operative needs. It is important to note that operators are a core element in the risk evaluation of subsea operations. Their motivation for preparation may significantly influence simulation-in-use and scheduled preparation procedure. Orlikowski [6] states that groupware is unlikely to lead to group work. We agree with this idea, and note that two different stages - development of simulators and team preparation in simulation environment - lead to two dissimilar infrastructures. In development of simulation and preparation of team procedure, no end users are present. Thus, to enable a richer safety approach for future preparation, we separate the two infrastructures to build the argument for involvement of operators in the preparation development.

Preparation procedures at the very beginning comprise a design process. Engineers influenced negotiations between simulation developers and decision makers from the oil and gas company, to identify the meaning of critical operations. The recurrent mechanism of operators' actions is beneficial for system development processes. While a simulator can be constructed with particular materials and inscribed with developers' and engineers' rulebooks and knowledge about the work context at a point, it is only when this simulator is used in recurrent simulator-in-practices that it can be said to structure end users' actions [7]. This represents a mutual verification process between the engineering and the simulation field. If we see the two infrastructures as two worlds, we can say the two are running to find a balance for the preparation process.

Engineers and technicians verified the procedures during the development process. There is less emphasis on the instructors' role in interpretation of activities and suggestions on the simulator's capacity, use, and value. In our case, the shift supervisor and the consultant from the oil and gas company committed to the evaluation role. However, instructors' abilities and responsibilities regarding safety issues should not be underestimated in the simulation development process.

Improving the process infrastructure could benefit future simulation. We argue that a new merged structure of a preparation process can serve safety purposes for all organisational entities.

\section{CONCLUSIONS}

In this article, we described a subsea installation preparation case. Findings of advantages for real operations were identified. We further suggested that merging of the simulation development and the team preparation infrastructures could benefit operational safety.

\section{ACKNOWLEDGEMENTS}

We would like to thank all informants, companies, and the university course department who enrolled in the interviews. We are also grateful to Professor Hans Petter Hildre for his support and constructive meetings. This research is founded by the Research Council of Norway.

\section{REFERENCES}

[1] Holland, J.H., Complexity: A Very Short Introduction, Oxford: Oxford University Press, 2014.

[2] Byrne, D., and G. Callaghan, Complexity Theory and the Social Sciences : the State of the Art, Routledge: London and New York, 2014. 
[3] Zeller, J., O.P. Riis, and G.S. Reinbacher, The Challenge of Complexity. Applied philosophy, Aalborg University Press: Aalborg, 2013.

[4] Saldaña, J., The Coding Manual for Qualitative Researchers, Sage: London; Thousand Oaks, CA, 2009.

[5] Bannon, L., From Human Factors to Human Actors: the Role of Psychology and Human-Computer Interaction Studies in System Design. Design at work, pp. 25-44, 1991.

[6] Orlikowski, W.J., Learning from Notes: Organizational Issues in Groupware Implementation. Proceedings of the 1992 ACM conference on Computer-supported cooperative work, ACM: Toronto, Ontario, Canada. pp. 362-369, 1992. http://dx.doi.org/10.1145/143457.143549

[7] Orlikowski, W., Using Technology and Constituting Structures: A Practice Lens for Studying Technology in Organizations. Resources, Co-Evolution and Artifacts, Springer: London, pp. 255-305, 2008. 